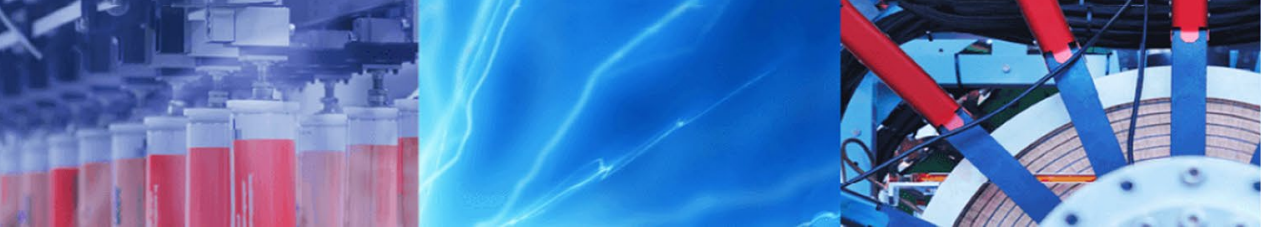

Research Article

\title{
A structural insight into the Chelyabinsk meteorite: neutron diffraction, tomography and Raman spectroscopy study
}

\author{
Sergey E. Kichanov ${ }^{1}$ (D) . Denis P. Kozlenko ${ }^{1}$ Andrey K. Kirillov ${ }^{2}$. Evgenii V. Lukin ${ }^{1}$ - Bekhzodjon Abdurakhimov ${ }^{1}$. \\ Nadeghda M. Belozerova' ${ }^{1}$. Anton V. Rutkauskas ${ }^{1} \cdot$ Tatiana I. Ivankina $^{1} \cdot$ Boris N. Savenko ${ }^{1}$
}

Received: 29 August 2019 / Accepted: 31 October 2019 / Published online: 6 November 2019

(c) Springer Nature Switzerland AG 2019

\begin{abstract}
The internal structural organization and phase composition of a fragment of the Chelyabinsk meteorite have been studied using neutron diffraction, tomography methods, optical microscopy, and Raman spectroscopy. The bulk mineral composition of the meteorite and spatial distribution of different components were determined. In addition to previously found phases of olivine, orthopyroxene, plagioclase and troilite, the obtained data of optical microscopy and neutron diffraction provide evidence of the presence of kamacite phase in the studied meteorite fragment. The heterogeneous distribution of the iron in the olivine and orthopyroxene phases was observed, the morphological calculations were used to analyze the spatial arrangement of metal components.
\end{abstract}

Keywords Meteorites · Non-destructive methods · Neutron diffraction · Neutron tomography $\cdot$ Raman spectroscopy

\section{Introduction}

One of the important problems in mineralogical and petrological research of meteorites and asteroids is an assessment of risks of the collisions of such astrophysical objects with the Earth, an estimation of influence of their structure and composition on the power of interaction with the atmosphere and a degree of energy release [1-3]. On February 15, 2013, over the Russian city of Chelyabinsk, a large asteroid with a mass of about 10 thousand tons entered the atmosphere at a speed of about $18 \mathrm{~km} / \mathrm{s}[4$, 5]. It was the largest collision event after Tunguska explosion in 1908 [4]. After that, the meteorite body destructed into thousands of small meteorite fragments and was accompanied by the spread of shock waves. The collision explosion was so powerful that the shock wave may twice round the Earth $[4,6,7]$. The particular attention should be paid to the fact that this meteorite collision led to the great destruction of buildings and injuries to thousands of people by broken glass mostly $[7,8]$.

Afterwards, the fragments of the meteorite body have been thoroughly investigated by various scientific methods [9-12]. It was found, that Chelyabinsk meteorite is a moderately shocked LL5 (S4, W0) ordinary chondrite [13] with olivine, pyroxene, plagioclase and iron as major mineral phases $[12,14]$. The possible origin of the meteorite from hazardous asteroid 1999 NC43 [15] of the Baptistina Asteroid Family in the main asteroid belt [16] is discussed. It is noted, unlike other LL chondrites, Chelyabinsk meteorite contains more metallic iron [17].

The measurements of the chemical composition and spatial distribution of components of the Chelyabinsk meteorite could gain new insights into its origin $[3,18$, 19]. Due to uniqueness of the meteoritic matter, an application of non-destructive testing methods provides particular advantages [18, 20,21]. The conventional methods like the $\mathrm{X}$-ray fluorescence analysis, scanning electron

Sergey E. Kichanov, ekich@nf.jinr.ru | 'FLNP, Joint Institute for Nuclear Research, Joliot-Curie st., 6, Dubna, Moscow Reg., Russia 141980. ${ }^{2}$ Institute for Physics of Mining Processes, Simferopolskay st., 2a, Dnipro 49600, Ukraine. 
microscopy or X-ray diffraction have a significant limitation on the depth of penetration into the thickness of the studied samples. Thus, the structural analysis of inner components of large fragments of meteorites may be difficult due to a fusion crust on the meteorite surface. In contrast, neutron diffraction and neutron tomography methods provide a non-destructive probe of structural organization of objects with high bulk penetration [22-26]. The fundamental difference in the nature of neutron interactions with matter compared to $\mathrm{X}$-rays provides additional benefits including sensitivity to light elements, a notable difference in contrast between neighboring elements like nickel and iron [18, 21, 22]. All these features make neutron methods highly demanded tool with a growing range of applications in industry [25], archeology [26, 27] and geophysics [28] including studies of meteorites [18, 20, 21].

In our work, the internal structural organization of the large fragment of Chelyabinsk meteorite has been studied by a combination of neutron tomography and neutron diffraction, supplemented by optical microscopy and Raman spectroscopy methods. The high neutron penetration depth inside the object allowed to detect the mineral phases of the bulk meteorite fragment, as well as to evaluate its average composition without the destruction of such a rare astrophysical object. The neutron methods can provide structural information about kamacite phase in the deep volume of the meteorite fragment.

\section{Experimental}

The studied fragment of Chelyabinsk meteorite was found on February 23, 2013 close to the enrichment plant of Deputatsky settlement near the Yemanzhelinsk (Chelyabinsk region, Russian Federation). The meteorite fragment of irregular shape with one lateral cavern has dimensions of approximately $31 \times 14 \times 11 \mathrm{~mm}$. It was covered with the fusion crust. A small area of the cavern was additionally cleaned to improve the optical microscope and Raman spectroscopy data.

The images from the cleavage of the meteorite with a maximum magnification of $x 12$ were obtained on the microscope Leica M165 with video camera set-up. Raman spectra at ambient temperature were collected using a LabRAM HR spectrometer (Horiba Gr, France) with a wavelength excitation of $633 \mathrm{~nm}$ emitted from He-Ne laser, 1800 grating, confocal hole of $100 \mu \mathrm{m}$, and $\times 50$ objective. A dozen Raman spectra were obtained from different local points of the small cleaned surface of the studied meteorite. The spectra had a rather low intensity, typical times of spectra acquisition varied from 5 up to $15 \mathrm{~min}$.

The phase composition of the whole meteorite fragment was examined using the DN-12 neutron diffractometer [29], operated at the IBR-2 high-flux pulsed reactor (Frank Laboratory for Neutron Physics, JINR, Dubna, Russia). The neutron powder diffraction patterns were collected at the scattering angle of $2 \theta=135.5^{\circ}$. The neutron diffraction patterns were analyzed by the profile matching mode using the Fullprof software [30]. In neutron diffraction experiments, the fragment of the meteorite was placed so that its middle part of average dimensions up to $8 \mathrm{~mm}$ was in the neutron beam. The exposition time was $1 \mathrm{~h}$.

The neutron tomography experiments were performed at the neutron radiography and tomography facility [31, 32] on the IBR-2 high-flux pulsed reactor. The detector system based on high sensitivity camera with HAMAMATSU CCD chip was used to a collection of neutron radiography images. The total number of measured radiography projections for tomography reconstruction procedure was 360 . The neutron experiments were performed with a rotation step of $0.5^{\circ}$. The exposure time for one projection was $20 \mathrm{~s}$. The obtained imaging data were corrected by the dark current image of digital camera and normalized to the image of the incident neutron beam by means of the ImageJ software [33]. The tomographic reconstruction was performed by the SYRMEP Tomo Project (STP) software [34]. Finally, a large data set containing a volume distribution of 3D pixels (voxels) were collected. The size of one voxel in our studies is $52 \times 52 \times 52 \mu \mathrm{m}$. The tomography reconstruction yields the set of 538 virtual slices. The $3 D$ volume data of voxels are the spatial distribution of values of the neutron attenuation coefficients inside the sample volume [35]. VGStudio MAX 2.2 software of Volume Graphics (Heidelberg, Germany) was used for visualization and analysis of reconstructed 3D data.

\section{Experimental results}

\subsection{Optical microscopy}

In order to obtain a visual representation of the distribution of components in the studied meteorite fragment, the conventional optical microscopy was used.

The fragment of the Chelyabinsk meteorite (Fig. 2) has a light lithology [9], where the main minerals are olivine and orthopyroxene $[10,14,36]$. The boundaries of the chondrules are not detected. An extensive network of cracks into meteorite material is visible. Even without a significant zoom of the images of the meteorite rift surface, the small metallic inclusions in the mineral substance are visible (Fig. 1). We assume that these metallic inclusions are kamacite FeNi grains. Size of these metallic grains on the studied area of the meteorite rift does not exceed 50-100 $\mu \mathrm{m}$. However, there are quite large (up to several 


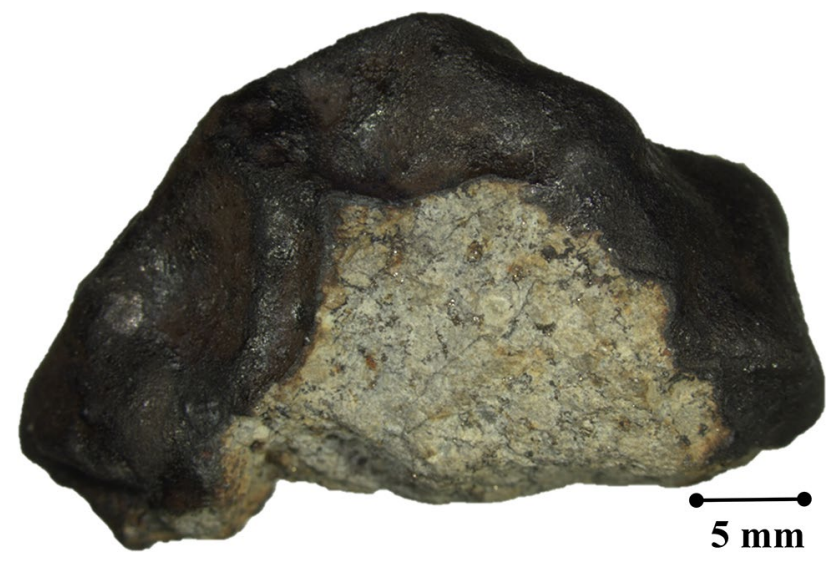

Fig. 1 The photography of the fragment of the Chelyabinsk meteorite. A scale bar is shown
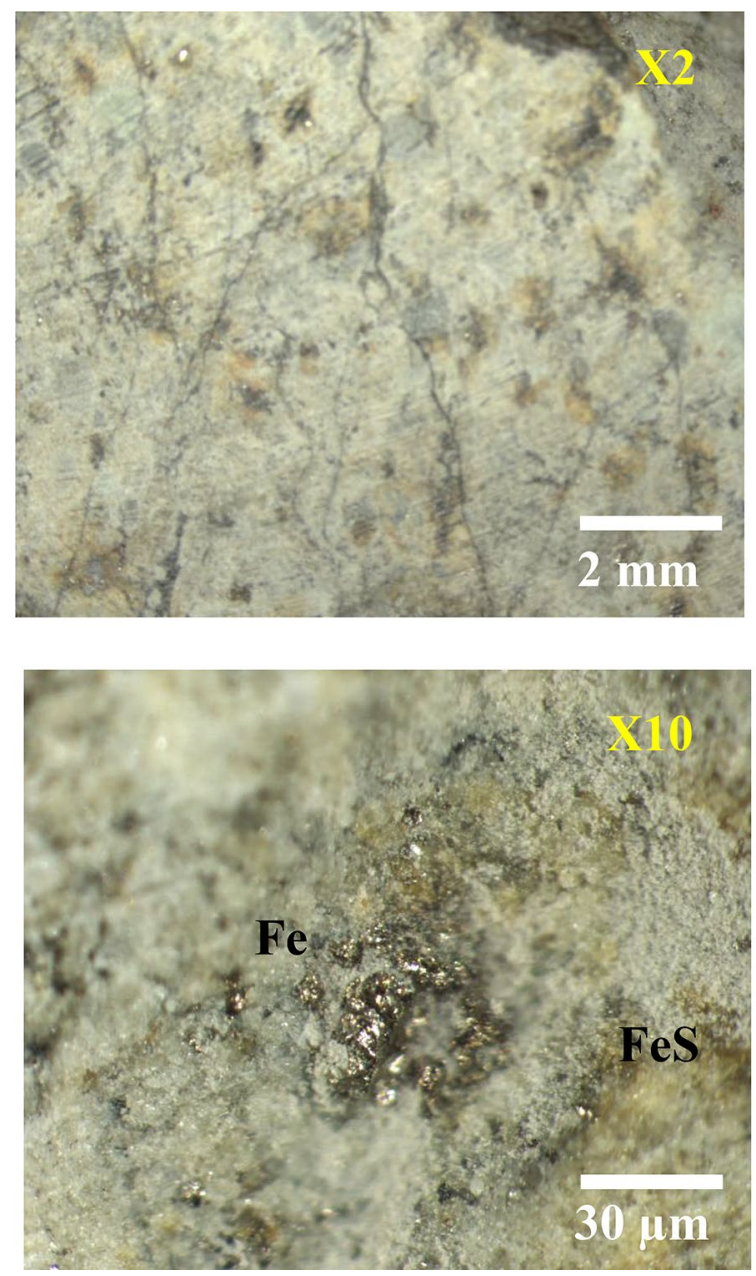

Fig. 2 Microphotographies of the surface of the cavern of the Chelyabinsk meteorite. The magnification levels and corresponding scales for each image are marked. The tentative assignment of millimeters) yellow areas around the observed inclusions (Fig. 1). It can be assigned to troilite, FeS. Large gray areas represent the orthopyroxene phase [9].

\subsection{Raman spectroscopy}

The Raman spectroscopy was used for the identification of mineral phases on the surface of the studied meteorite. A set of Raman spectra was collected from dozen points on the meteorite rift surface, and several representative Raman spectra of the main phases of the Chelyabinsk meteorite are shown in Fig. 3.

The factor group analysis predicts that olivine with orthorhombic symmetry Pnma has 36 Raman-active vibration modes: $11 \mathrm{~A}_{\mathrm{g}}+11 \mathrm{~B}_{1 \mathrm{~g}}+7 \mathrm{~B}_{2 \mathrm{~g}}+7 \mathrm{~B}_{3 \mathrm{~g}}[37,38]$. There are two intense characteristic Raman lines of olivine at 820.8 and $852.4 \mathrm{~cm}^{-1}$ on Raman spectra (Fig. 2). Those lines correspond to $\mathrm{Si}-\mathrm{O}$ asymmetric and symmetric stretching $A_{g}$ mods. It should be noted that the
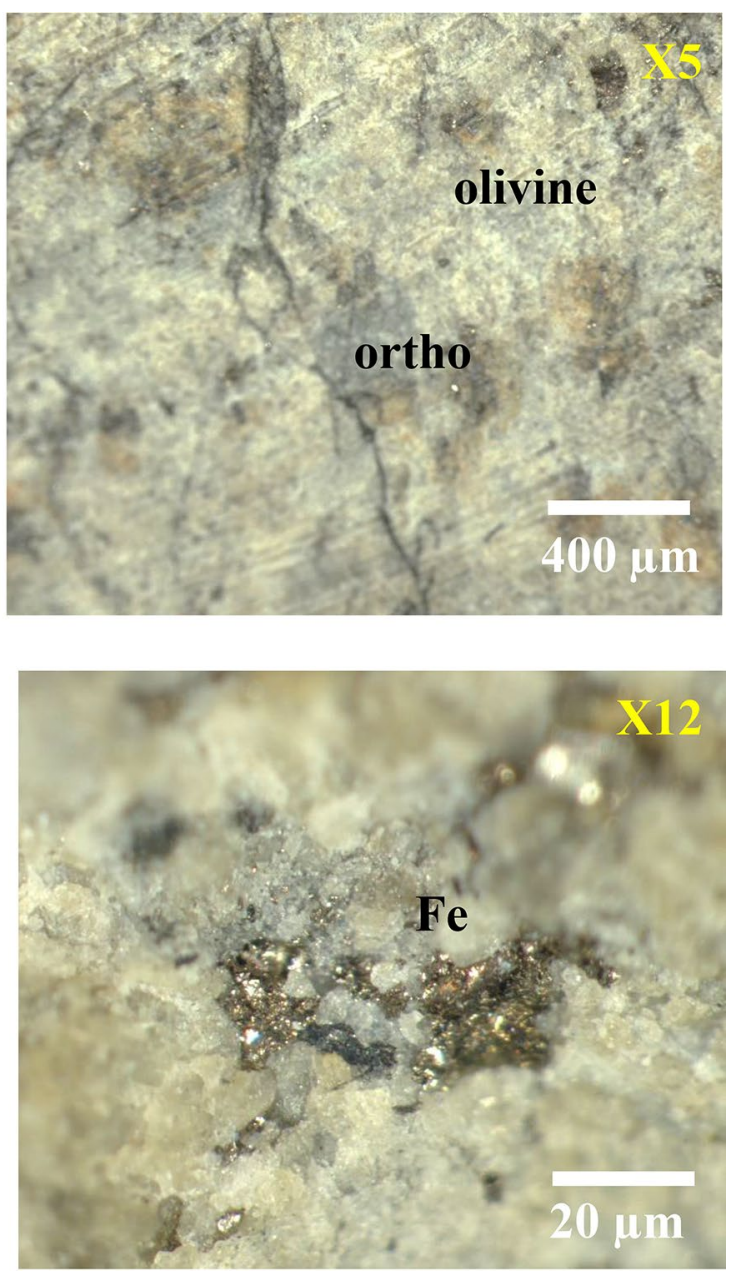

several meteorite fractions: olivine (olivine), orthopyroxene (ortho), troilite (FeS), and kamacite ( $\mathrm{Fe}$ ) are shown 


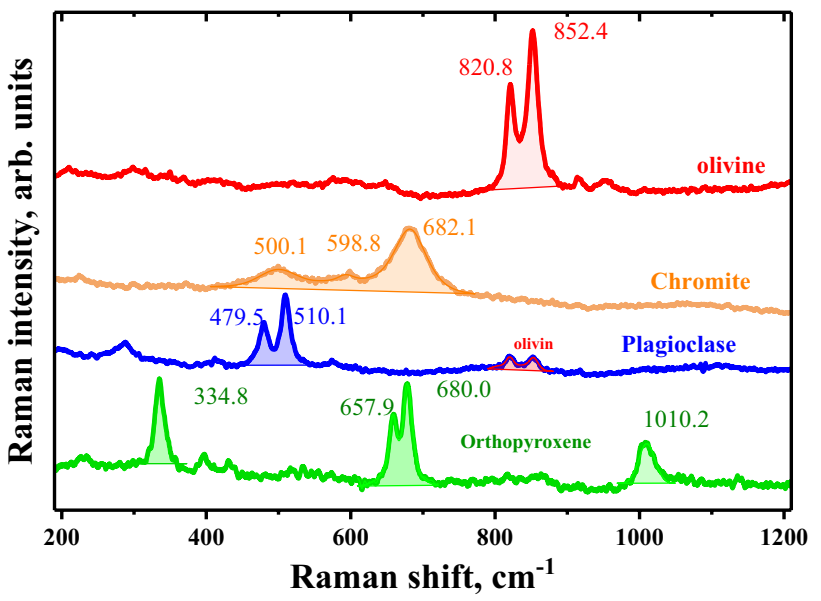

Fig. 3 Raman spectra obtained from different points of the Chelyabinsk meteorite surface and corresponding to different mineral phases. The observed Raman wavenumbers of most intense Raman peaks are indicated

relative positions of these Raman lines can be used in the estimation of the relative content of fayalite $\mathrm{Fa}\left(\mathrm{Fe}_{2} \mathrm{SiO}_{4}\right)$ and forsterite Fo $\left(\mathrm{Mg}_{2} \mathrm{SiO}_{4}\right)$ minerals $[37,38]$ in the olivine. If the difference between the positions of Raman peaks equals to $\Delta=31.6(1) \mathrm{cm}^{-1}$, then the olivine mineral composition is estimated as $\sim \mathrm{Fo}_{70} \mathrm{Fa}_{30}$. This value agrees well with data obtained early $[9,38]$.

The Raman spectrum for the orthopyroxene mineral component is shown in Fig. 3. The characteristic Raman lines at 334.8(2), 657.9(2), 680.0(2) and $1010 \mathrm{~cm}^{-1}$ are clearly visible. Since the Raman spectra of orthopyroxene and clinopyroxene are similar $[37,38]$, we can assume that a small contribution of the clinopyroxene phase may be also present. For orthopyroxene, the end-members are enstatite $\mathrm{En}$, with mineral formula $\mathrm{Mg}_{2} \mathrm{Si}_{2} \mathrm{O}_{6}$, and ferrosilite $\mathrm{Fs}$, with mineral formula $\mathrm{Fe}_{2} \mathrm{Si}_{2} \mathrm{O}_{6}[3,37]$. On the basis of the Raman spectroscopy data of minerals of $\mathrm{LL}$ chondrites [37], we can evaluate the average content of orthopyroxene as $\mathrm{En}_{80-70} \mathrm{Fs}_{20-30}$ for the fragment of the Chelyabinsk meteorite.

In our experiments, the characteristic Raman spectra of plagioclase phase component $[10,36]$ were also found (Fig. 3). There are doublet at 475.5(2) and 510.1(2) as well as the weak line at $288.5(2) \mathrm{cm}^{-1}$. It is known that plagioclase is a solid solution of the albite $\mathrm{Ab}\left(\mathrm{NaAlSi}_{3} \mathrm{O}_{8}\right)$ and anorthite $\mathrm{An}\left(\mathrm{CaAl}_{2} \mathrm{Si}_{2} \mathrm{O}_{8}\right)$ minerals. Comparison of observed Raman data with results of systematic Raman spectroscopy studies of plagioclase in different chondrites $[39,40]$ suggests that the composition of plagioclase in the Chelyabinsk meteorite is similar to meteorite sample 97490 from Pegmatitic, Head of Little Rock Creek,

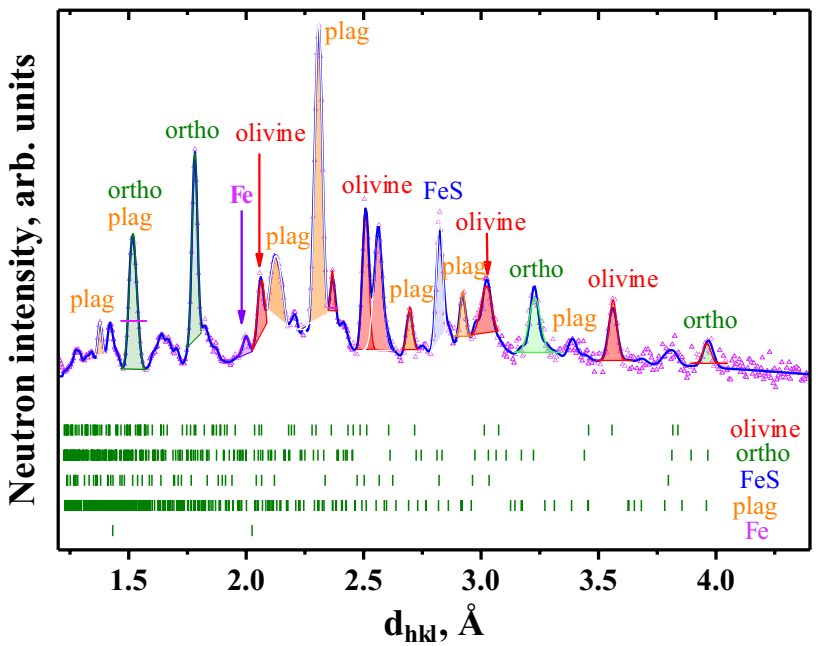

Fig. 4 Neutron diffraction patterns of the fragment of the Chelyabinsk meteorite. The experimental points and calculated profile are shown. Ticks below represent calculated positions of the Bragg peaks of the observed phases: olivine, orthopyroxene (ortho), plagioclase (plag), troilite (FeS) and kamacite (Fe). The corresponding diffraction peaks are marked

Mitchell County, N. Carolina [41]. Thus, the tentative plagioclase formula is $\mathrm{An}_{27} \mathrm{Ab} \mathrm{b}_{73}$.

One of the obtained Raman spectra corresponds to the chromite phase (Fig. 3). Chromite has a normal spinel structure and belongs to the $F d \overline{3} m$ space group. The Raman spectra show a major broad peak at $682.1(2) \mathrm{cm}^{-1}$. This peak assigned to the $A_{1 g}$ mode and corresponds to vibration of $\left(\mathrm{Cr}^{3+}, \mathrm{Fe}^{3+}, \mathrm{Al}^{3+}\right) \mathrm{O}_{6}$ octahedra. The position of this peak indicates that the content of aluminum in the chromite does not exceed 20\% [39].

It should be noted that Raman spectroscopy is very useful tool for the identification of the mineral composition of meteorites and the evaluation of the chemical composition of these minerals. However, obtained data, as well as in optical microscopy, corresponds to the surface of the meteorite cleavage. Thus, neutron diffraction was used to study the mineral composition of the bulk of Chelyabinsk meteorite.

\subsection{Neutron diffraction}

The neutron diffraction pattern of the fragment of the Chelyabinsk meteorite is shown in Fig. 4. A rather complex background of the neutron pattern implies a presence of some fraction of the amorphous phase [12]. The observed diffraction peaks attributed to the main minerals composition of the Chelyabinsk meteorite [10,42] such as olivine, orthopyroxene, and plagioclase. Several weak peaks correspond to the hexagonal phase of troilite $\mathrm{FeS}$ and cubic kamacite FeNi. The unit cell parameters obtained from the 
Table 1 The obtained unit cell parameters of main phases of the Chelyabinsk meteorite

\begin{tabular}{lll}
\hline Phase name & Space group & Lattice parameters \\
\hline Olivine & $P b n m$ & $a=4.787(3) \AA, b=10.222(1) \AA, c=6.049(2) \AA$ \\
Orthopyroxene & $P b c a$ & $a=18.240(4) \AA, b=8.926(3) \AA, c=5.228(2) \AA$ \\
Plagioclase & $P \overline{1}$ & $a=8.15 \AA, b=12.74 \AA, c=14.149(2) \AA$ \\
& & $a=93.38^{\circ} \beta=115.4^{\circ} \gamma=89.0^{\circ}$ \\
Troilite & $P \overline{6} 2 c$ & $a=5.956(5) \AA, c=11.749(5) \AA$ \\
Kamacite & $I m \overline{3} m$ & $a=2.871(8) \AA$
\end{tabular}

neutron diffraction data are listed in Table 1. The obtained structural parameters for the mineral phases of the Chelyabinsk meteorite are in a good agreement with those previously reported [36].

The predominant phase of the studied fragment of Chelyabinsk meteorite is olivine [12]. From the obtained lattice parameters of this mineral, we can estimate their relative content [42]. Our estimations yield the composition of olivine in the studied meteorite as $\mathrm{Fo}_{75} \mathrm{Fa}_{25}$. This value is consistent well with the results of Raman spectroscopy (Sect. 3.2) or data obtained by other methods [36].

The second main phase in the composition of the Chelyabinsk meteorite is orthopyroxene with the orthorhombic crystal structure [12,36]. The unit cell parameters of this phase are listed in Table 1. The obtained structural parameters were used to estimate the elements content in accordance with the empirical relationships between unit cell parameters and chemical composition of main meteorite minerals [42]. Thus, the relative iron content in orthopyroxene was estimated as $\frac{\mathrm{Fe}}{\mathrm{Fe}+\mathrm{Mg}}=0.16(2)$, while the relative calcium content is close to zero. The estimation of the relative composition of enstatite and ferrosilite minerals in orthopyroxene [42] gives the value $\mathrm{En}_{58} \mathrm{Fs}_{42}$. The estimated content of ferrosilite exceeds slightly those obtained from Raman spectroscopy (Sect. 3.2) or in other studies [35, 36]. We believe this is explained by the rough averaging over the entire volume of the meteorite in our neutron diffraction experiments.

Several peaks corresponding to plagioclase phase were observed in the neutron diffraction patterns (Fig. 4). However, due to complexity of the crystal structure and overlapping of relevant diffraction peaks, it was difficult to obtain the unit cell parameters accurately and only estimation of these parameters is given in the Table 1.

There are several shoulder peaks, which can be attributed to the iron sulfide phase FeS and kamacite FeNi impurity in the Chelyabinsk meteorite. The obtained unit cell parameters of kamacite indicate a low nickel content $(<6 \%)$ in this mineral [42].

\subsection{Neutron tomography}

While neutron diffraction was used to identify the mineral phase composition of the studied meteorite fragment, the spatial distribution of the minerals was analysed by neutron tomography.

A set of 360 neutron radiographic images for the different angular position of the sample relative to the beam direction was used in the 3D tomography reconstruction $[18,35]$ of the inner structure of the Chelyabinsk meteorite (Fig. 5). The neutron attenuation coefficients for a neutron beam with an average wavelength of $\sim 2 \AA$ of iron composed components are scientifically larger than the relevant parameters for olivine, orthopyroxene or clinopyroxene. Therefore, the metallic particles have a good contrast with respect to the silicate-based components in the neutron tomography experiments. In our work, the metallic inclusions visible in the optical microscopy, and the weak diffraction peak in the neutron diffraction experiments are attributed to the kamacite FeNi.

As an example, several virtual slices of the reconstructed 3D model of the Chelyabinsk meteorite fragment are presented in Fig. 5. The observed well-distinguishable several rounded large grains and a dozen small kamacite grains do not exceed a size of 1-3 mm. The 3D virtual volume of the whole fragment of the Chelyabinsk meteorite is formed by 25378272 voxels, which corresponds to the volume of $3996.11 \mathrm{~mm}^{3}$. The metal grains volume comprises $309.15 \mathrm{~mm}^{3}$. It should be noted that the spatial resolution of the neutron tomography method does not allow to detect small particles and veins of the metal phase, so the calculations of the kamasite content in the volume of the fragment of Chelyabinsk meteorite should be considered as estimates. As a result, the estimated volume fraction of kamacite components in meteorite fragment is $7.7 \%$.

The distribution of the metallic grains inside the studied fragment and their volume distribution is shown in Fig. 6a, b.

We calculated several statistical parameters for the observed metal grains. Thus, the average volume of 


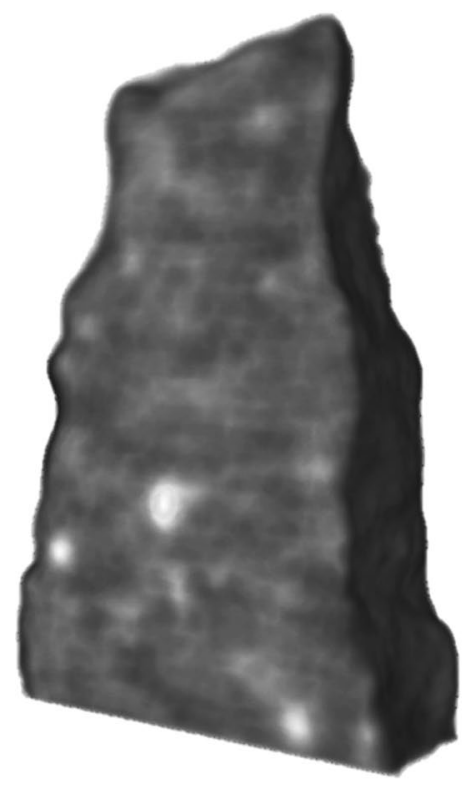

Fig. 5 The several virtual slices of the 3D model of the fragment of the Chelyabinsk meteorite after tomographic reconstruction. The bright regions correspond to high neutron attenuation in the
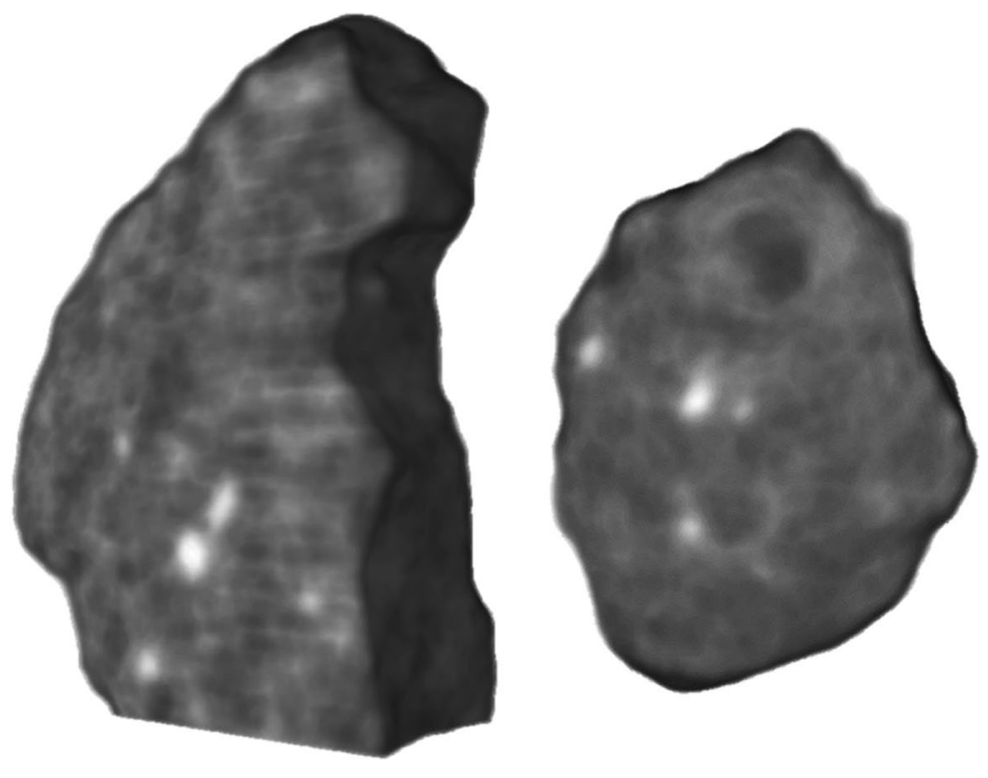

metallic component. The gray areas are low neutron attenuation regions of silicate-based minerals

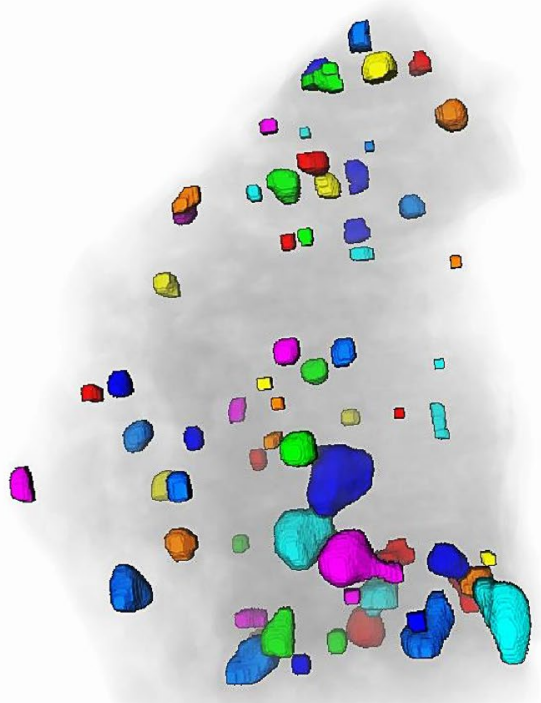

(a)

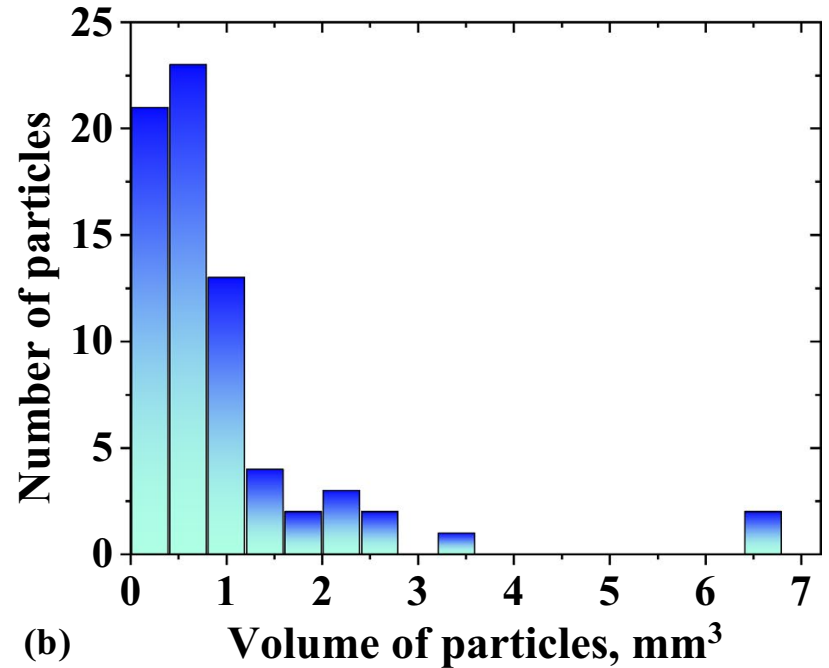

(b)

Fig. 6 a The separated 3D virtual areas correspond to kamacite grains inside the fragment of the Chelyabinsk meteorite. $\mathbf{b}$ The volume distribution for separated grains

the observed iron-rich regions is 0.89 (3) $\mathrm{mm}^{3}$, but the median value is $0.48(2) \mathrm{mm}^{3}$. An equivalent diameter [43] describes average sizes shapeless grain. The calculated distribution of the equivalent diameters of the metal particles is presented in Fig. 7a. The characteristic sizes of the most iron grains fall into the range of $1-2 \mathrm{~mm}$, the larger diameter is $2.42(5) \mathrm{mm}$. Several morphological parameters can be calculated [18]. As an example, the distribution of sphericity parameter [43] is shown in Fig. 7b. The studied metal grains inside the fragment of Chelyabinsk meteorite are described by

\section{SN Applied Sciences}



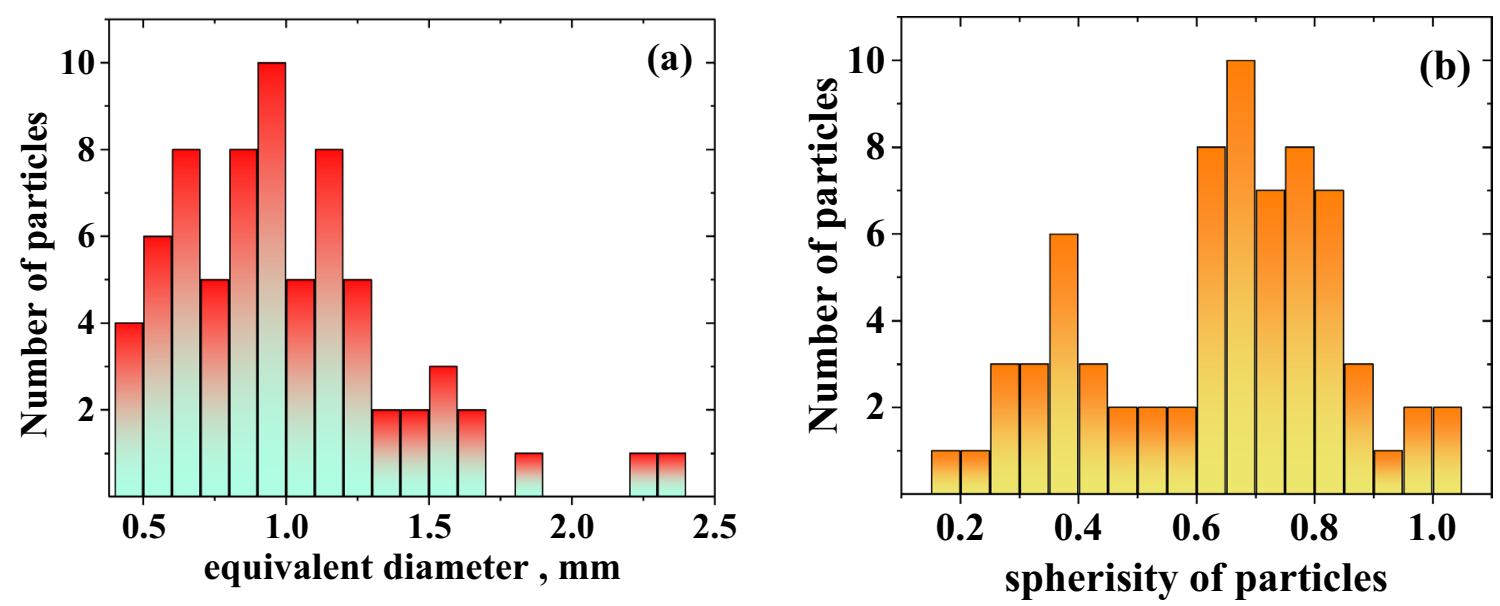

Fig. 7 a The distribution of the equivalent diameters of the observed metallic grains of the fragment of the Chelyabinsk meteorite. $\mathbf{b}$ The distribution of the sphericity parameter for iron-rich areas inside the Chelyabinsk meteorite

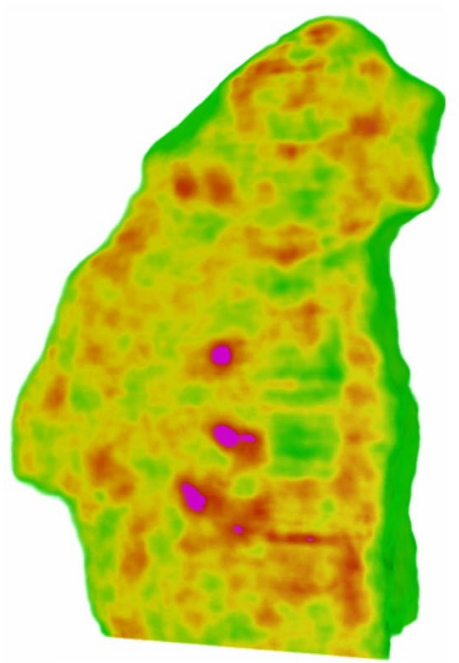

Fig. 8 The clipped virtual 3D model of the Chelyabinsk meteorite fragment. The rainbow-like coloring shows neutron attenuation from low (green) to high (red) degree. The coloring scale corre-
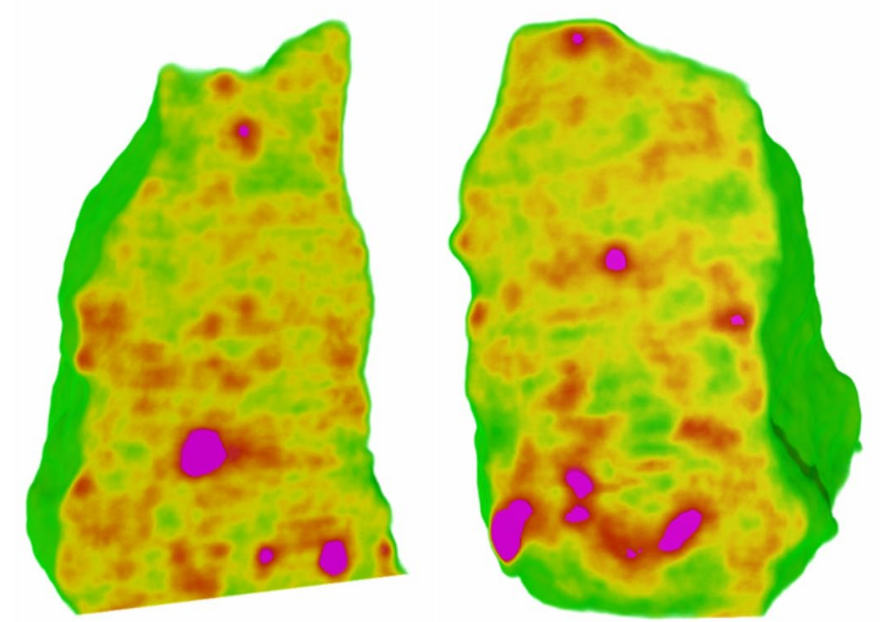

0.2

0.15

0.1

0.05

0.01 close-to-spherical shapes with sphericity of $\sim 0.8$, and more rough forms with the sphericity of around $\sim 0.4$.

An interesting result from the obtained neutron tomography data is a heterogeneous distribution of neutron attenuation lengths inside the volume of related silicate minerals (Fig. 8). According to the corresponding neutron total cross-section data tables [44] for the expected elements, we can assume that it is associated with changes in the sponding to relative neutron attenuation lengths is shown. The metal grains are labeled in pink

concentration of the iron composition in corresponding silicate minerals [18]. We suggest that higher absorption relates to Fe-rich areas. It is interesting to note that these areas are mainly concentrated around the metal grains, which may indicate the intensive exchange of the iron between the metal components and olivine minerals [45]. Those Fe-rich areas volumes occupy $1981.71 \mathrm{~mm}^{3}$ or $42.6 \%$ of the total silicate based material volume of the meteorite fragment. 


\section{Conclusions}

In the present work, a bulk internal organization of the Chelyabinsk meteorite was analysed by a combination of neutron diffraction, tomography, Raman spectroscopy and optical microscopy methods. The high neutron penetration depth inside the object allowed to determine the mineral composition of the bulk meteorite fragment, as well as to evaluate its average phase composition. A sharp contrast in the neutron attenuation coefficients between metal and silica components enabled us to clarify specific structural features of the meteorite. Neutron diffraction indicates presence of kamacite in the volume of the meteorite fragment. The rather large grains of kamacite and troilite were found in the inner volume of the studied fragment of the Chelyabinsk meteorite by means of neutron tomography. The size distribution and the morphological features of those iron-rich grains were obtained. The inhomogeneous distribution of iron in olivine and orthopyroxene may identify iron-exchange processes between silicate minerals and iron-containing compounds.

Acknowledgements The authors acknowledge Perevozov A.A. (South Ural State Humanitarian Pedagogical University, Chelyabinsk, Russia) for providing the fragment of Chelyabinsk meteorite for the studies.

Author contributions All authors contributed to the study conception and design. Meteorite collection and preparation for experiments were performed by AKK. Data collection and analysis were performed by EVL, BA, NMB and AVR. The results discussions were performed by SK, DK, TI and BS. The first draft of the manuscript was written by SK and DK. All authors are familiar with the text of the draft of manuscript and commented it. All authors read and approved the final manuscript.

\section{Compliance with ethical standards}

Conflict of interest The authors declare no conflicts of interest.

\section{References}

1. Rumpf CM, Lewis HG, Atkinson PM (2017) Asteroid impact effects and their immediate hazards for human populations. Geophys Res Lett 44:3433-3440. https://doi.org/10.1002/2017G L073191

2. Bischoff A, Stöffler D (1992) Shock metamorphism as a fundamental process in the evolution of planetary bodies: Information from meteorites. Eur J Mineral 4:707-756. https://doi. org/10.1127/ejm/4/4/0707

3. Van Schmus WR (1969) The mineralogy and petrology of chondritic meteorites. Earth-Sci Rev 5:145-184. https://doi. org/10.1016/0012-8252(69)90076-2

4. Popova OP, Jenniskens P, Emel'yanenko V, Kartashova A, Biryukov E, Khaibrakhmanov S, Shuvalov V, Rybnov Y, Dudorov A, Grokhovsky VI, Badyukov DD, Yin Q-Z, Gural PS, Albers J, Granvik M, Evers LG, Kuiper J, Kharlamov V, Solovyov A, Rusakov YS,
Korotkiy S, Serdyuk I, Korochantsev AV, Larionov MY, Glazachev D, Mayer AE, Gisler G, Gladkovsky SV, Wimpenny J, Sanborn ME, Yamakawa A, Verosub KL, Rowland DJ, Roeske S, Botto NW, Friedrich JM, Zolensky ME, Le L, Ross D, Ziegler K, Nakamura T, Ahn I, Lee JI, Zhou Q, Li X-H, Li Q-L, Liu Y, Tang G-Q, Hiroi T, Sears D, Weinstein IA, Vokhmintsev AS, Ishchenko AV, Schmitt-Kopplin $P$, Hertkorn N, Nagao K, Haba MK, Komatsu M, Mikouchi T, Chelyabinsk Airburst Consortium (2013) Chelyabinsk airburst, damage assessment, meteorite recovery, and characterization. Science 80(342):1069-1073. https://doi.org/10.1126/science.12426 42

5. Miller SD, Straka WC, Bachmeier AS, Schmit TJ, Partain PT, Noh Y-J, Noh Y-J (2013) Earth-viewing satellite perspectives on the Chelyabinsk meteor event. Proc Natl Acad Sci USA 110:1809218097. https://doi.org/10.1073/pnas.1307965110

6. Trieloff $M$, Korochantseva EV, Buikin Al, Hopp J, Ivanova MA, Korochantsev AV (2018) The Chelyabinsk meteorite: thermal history and variable shock effects recorded by the 40Ar-39Ar system. Meteor Planet Sci 53:343-358. https://doi.org/10.1111/ maps.13012

7. Brown PG, Assink JD, Astiz L, Blaauw R, Boslough MB, Borovička J, Brachet N, Brown D, Campbell-Brown M, Ceranna L, Cooke W, de Groot-Hedlin C, Drob DP, Edwards W, Evers LG, Garces M, Gill J, Hedlin M, Kingery A, Laske G, Le Pichon A, Mialle P, Moser DE, Saffer A, Silber E, Smets P, Spalding RE, Spurný P, Tagliaferri E, Uren D, Weryk RJ, Whitaker R, Krzeminski Z (2013) A 500-kiloton airburst over Chelyabinsk and an enhanced hazard from small impactors. Nature 503:238-241. https://doi.org/10.1038/natur e12741

8. Brumfiel G (2013) Russian meteor largest in a century. Nature. https://doi.org/10.1038/nature.2013.12438

9. Kaeter D, Ziemann MA, Böttger U, Weber I, Hecht L, Voropaev SA, Korochantsev AV, Kocherov AV (2018) The Chelyabinsk meteorite: new insights from a comprehensive electron microscopy and Raman spectroscopy study with evidence for graphite in olivine of ordinary chondrites. Meteor Planet Sci 53:416-432. https://doi.org/10.1111/maps.13027

10. Righter K, Abell P, Agresti D, Berger EL, Burton AS, Delaney JS, Fries MD, Gibson EK, Haba MK, Harrington R, Herzog GF, Keller LP, Locke D, Lindsay FN, McCoy TJ, Morris RV, Nagao K, Nakamura-Messenger K, Niles PB, Nyquist LE, Park J, Peng ZX, Shih C-Y, Simon JI, Swisher CC, Tappa MJ, Turrin BD, Zeigler RA (2015) Mineralogy, petrology, chronology, and exposure history of the Chelyabinsk meteorite and parent body. Meteor Planet Sci 50:1790-1819. https://doi.org/10.1111/maps.12511

11. Pavlov DA, Bobrov Al, Malekhonova NV, Pirogov AV, Nezhdanov AV (2015) Self-assembled nanocrystals discovered in Chelyabinsk meteorite. Sci Rep 4:4280. https://doi.org/10.1038/srep0 4280

12. Moroz TN, Goryainov SV, Pokhilenko NP, Podgornykh NM (2014) Crystalline and amorphous matter in the Chelyabinsk meteorite: evidence from Raman spectroscopy. Dokl Earth Sci 457:831834. https://doi.org/10.1134/S1028334X14070071

13. Ruzicka A, Grossman J, Bouvier A, Herd CDK, Agee CB (2015) The Meteoritical Bulletin, No. 102. Meteor Bull 8:1662

14. Antipin VS, Kuz'min MI, Pecherskii DM, Tsel'movich VA, Yazev SA (2014) The substance of the Chelyabinsk meteorite: Results of geochemical and thermomagnetic studies. Dokl Earth Sci 458:1082-1085. https://doi.org/10.1134/s1028334x14090013

15. Reddy V, Vokrouhlický D, Bottke WF, Pravec P, Sanchez JA, Gary BL, Klima R, Cloutis EA, Galád A, Guan TT, Hornoch K, Izawa MRM, Kušnirák P, Le Corre L, Mann P, Moskovitz N, Skiff B, Vraštil J (2015) Link between the potentially hazardous Asteroid (86039) 1999 NC43 and the Chelyabinsk meteoroid tenuous. Icarus 252:129-143. https://doi.org/10.1016/J.ICARUS.2015.01.006 
16. Reddy V, Sanchez JA, Bottke WF, Cloutis EA, Izawa MRM, O'Brien DP, Mann P, Cuddy M, Le Corre L, Gaffey MJ, Fujihara G (2014) Chelyabinsk meteorite explains unusual spectral properties of Baptistina Asteroid Family. Icarus 237:116-130. https://doi. org/10.1016/J.ICARUS.2014.04.027

17. Roshchin VE, Goikhenberg YN, Galimov DM (2014) Native metal of the Chelyabinsk meteorite. Russ Metall 2014:419-425. https ://doi.org/10.1134/S0036029514050103

18. Kichanov SE, Kozlenko DP, Lukin EV, Rutkauskas AV, Krasavin EA, Rozanov AY, Savenko BN (2018) A neutron tomography study of the Seymchan pallasite. Meteor Planet Sci 53:2155-2164. https ://doi.org/10.1111/maps.13115

19. Hezel DC, Friedrich JM, Uesugi M (2013) Looking inside: 3D structures of meteorites. Geochim Cosmochim Acta 116:1-4. https://doi.org/10.1016/j.gca.2013.01.012

20. Caporali S, Grazzi F, Salvemini F, Garbe U, Peetermans S, Pratesi G, Caporali S, Grazzi F, Salvemini F, Garbe U, Peetermans S, Pratesi G (2016) Structural characterization of iron meteorites through neutron tomography. Minerals 6:14. https://doi. org $/ 10.3390 / \min 6010014$

21. Fedrigo A, Marstal K, Bender Koch C, Andersen DahI V, Bjorholm Dahl A, Lyksborg M, Gundlach C, Ott F, Strobl M, Fedrigo A, Marstal K, Bender Koch C, Andersen Dahl V, Bjorholm Dahl A, Lyksborg M, Gundlach C, Ott F, Strobl M (2018) Investigation of a Monturaqui Impactite by means of bi-modal X-ray and neutron tomography. J Imaging 4:72. https://doi.org/10.3390/jimag ing 4050072

22. Hussey DS, Jacobson DL (2015) Applications of neutron imaging and future possibilities. Neutron News 26:19-22. https://doi. org/10.1080/10448632.2015.1028273

23. Schwarz D, Vontobel P, Lehmann EH, Meyer CA, Bongartz G (2005) Neutron tomography of internal structures of vertebrate remains: a comparison with X-ray computed tomography. Palaentologia Electronica 8(2):30A. https://palaeo-electronica.org/ paleo/2005_2/icht/issue2_05.htm

24. Lehmann $E$ (2017) Neutron imaging facilities in a global context. J Imaging 3:52. https://doi.org/10.3390/jimaging3040052

25. Grünzweig C, Mannes D, Kaestner A, Schmid F, Vontobel P, Hovind J, Hartmann S, Peetermans S, Lehmann E (2013) Progress in industrial applications using modern neutron imaging techniques. Phys Procedia 43:231-242. https://doi.org/10.1016/J. PHPRO.2013.03.027

26. Kardjilov N, Festa G (Eds) (2017) Neutron Methods for Archaeology and Cultural Heritage. Springer International Publishing. https://doi.org/10.1007/978-3-319-33163-8_16

27. Kichanov S, Saprykina I, Kozlenko D, Nazarov K, Lukin E, Rutkauskas A, Savenko B, Kichanov S, Saprykina I, Kozlenko D, Nazarov K, Lukin E, Rutkauskas A, Savenko B (2018) Studies of ancient russian cultural objects using the neutron tomography method. $\mathrm{J}$ Imaging 4:25. https://doi.org/10.3390/jimaging4020025

28. Kaestner A, Vontobel P, Lehmann E (2013) Neutron imaging methods in geoscience. In: Alshibli KA, Reed AH (eds) Advances in computed tomography for geomaterials. Wiley, Hoboken, NJ, pp 352-365

29. Aksenov VL, Balagurov AM, Glazkov VP, Kozlenko DP, Naumov IV, Savenko BN, Sheptyakov DV, Somenkov VA, Bulkin AV (1999) Time-of-flight neutron diffractometer for investigation of microsamples under high external pressure. Phys B Condens Matter 241-243:219-220. https://doi.org/10.1016/S0921 $-4526(97) 00556-5$

30. Rodríguez-Carvajal J (1993) Recent advances in magnetic structure determination by neutron powder diffraction. Phys B Condens Matter 192:55-69. https://doi.org/10.1016/09214526(93)90108-I

31. Kozlenko DP, Kichanov SE, Lukin EV, Rutkauskas AV, Bokuchava GD, Savenko BN, Pakhnevich AV, Rozanov AY (2015) Neutron radiography facility at IBR-2 high flux pulsed reactor: first results. Phys Procedia 69:87-91. https://doi.org/10.1016/J.PHPRO .2015.07.012

32. Kozlenko DP, Kichanov SE, Lukin EV, Rutkauskas AV, Belushkin AV, Bokuchava GD, Savenko BN (2016) Neutron radiography and tomography facility at IBR-2 reactor. Phys Part Nucl Lett 13:346-351. https://doi.org/10.1134/S1547477116030146

33. Schneider CA, Rasband WS, Eliceiri KW (2012) NIH image to ImageJ: 25 years of image analysis. Nat Methods 9:671-675. https://doi.org/10.1038/nmeth.2089

34. Brun F, Massimi L, Fratini M, Dreossi D, Billé $F$, Accardo A, Pugliese $R$, Cedola A (2017) SYRMEP Tomo project: a graphical user interface for customizing CT reconstruction workflows. Adv Struct Chem imaging 3:4. https://doi.org/10.1186/s40679-016-0036-8

35. Lehmann EH, Kaestner AP (2009) 3D neutron imaging. In: Mayers RA (ed) Encyclopedia of analytical chemistry: applications, theory and instrumentation. Wiley, Chichester

36. Lutoev VP, Potapov SS, Isaenko SI, Lysyuk AYu, Simakova YuS, Samotolkova MF (2013) Mineral substance of the meteorite Chelyabinsk: infrared absorbtion, Raman and 57Fe Mossbauer spectroscopy. Bull Inst Geol Komi Sci Cent URD RAS 7:2-9

37. Mouri T, Enami M (2008) Raman spectroscopic study of olivinegroup minerals. J Mineral Petrol Sci 103:100-104. https://doi. org/10.2465/jmps.071015

38. Breitenfeld LB, Dyar MD, Carey CJ, Tague TJ, Wang P, Mullen T, Parente M (2018) Predicting olivine composition using Raman spectroscopy through band shift and multivariate analyses. Am Mineral 103:1827-1836. https://doi.org/10.2138/am-2018-6291

39. Pittarello L, Baert K, Debaille V, Claeys P (2015) Screening and classification of ordinary chondrites by Raman spectroscopy. Meteor Planet Sci 50:1718-1732. https://doi.org/10.1111/ maps.12506

40. Bersani D, Aliatis I, Tribaudino M, Mantovani L, Benisek A, Carpenter MA, Gatta GD, Lottici PP (2018) Plagioclase composition by Raman spectroscopy. J Raman Spectrosc 49:684-698. https ://doi.org/10.1002/jrs.5340

41. Wang A, Kuebler KE, Jolliff BL, Haskin LA (2004) Raman spectroscopy of Fe-Ti-Cr-oxides, case study: Martian meteorite EETA79001. Am Mineral 89:665-680. https://doi.org/10.2138/ am-2004-5-601

42. Morrison SM, Downs RT, Blake DF, Prabhu A, Eleish A, Vaniman DT, Ming DW, Rampe EB, Hazen RM, Achilles CN, Treiman AH, Yen AS, Morris RV, Bristow TF, Chipera SJ, Sarrazin PC, Fendrich KV, Morookian JM, Farmer JD, Des Marais DJ, Craig PI (2018) Relationships between unit-cell parameters and composition for rock-forming minerals on Earth, Mars, and other extraterrestrial bodies. Am Mineral 103:848-856. https://doi.org/10.2138/ am-2018-6123

43. Gregorová $E$, Pabst $W$, Vaněrková L, Nakagawa $M$, Luding $S$ (2009) Anisometric particle systems-from shape characterization to suspension rheology. In: AIP conference proceedings. AIP, pp 1027-1030

44. Sears VF (1992) Neutron scattering lengths and cross sections. Neutron News 3:26-37. https://doi.org/10.1080/1044863920 8218770

45. Friedrich JM, Wignarajah DP, Chaudhary S, Rivers ML, Nehru CE, Ebel DS (2008) Three-dimensional petrography of metal phases in equilibrated $L$ chondrites-Effects of shock loading and dynamic compaction. Earth Planet Sci Lett 275:172-180. https://doi.org/10.1016/J.EPSL.2008.08.024

Publisher's Note Springer Nature remains neutral with regard to jurisdictional claims in published maps and institutional affiliations. 